\title{
Life Skills Development through School Education
}

\author{
Dr. Prof. T. F Gulhane \\ Rajiv Gandhi College of Engineering Research \& Technology, Chandrapur, Maharashtra, India.
}

\begin{abstract}
As part of the life skills program there are close links between the department and other subjects, including Science, RS, Thinking Skills, Current Affairs and Games/ PE. Life skills are also developed through assemblies, which are led by individual members of staff and by forms or other groups. A life skill encourages capacity to think rationally both inside and outside the classroom.
\end{abstract}

Keywords: Life skills, abilities, UNICEF, Child rights.

\section{Introduction}

The Life Skills program is central to the life and ethos of the High School. Indeed, it could be argued that the whole of the school day is involved in the delivery of Life Skills.

Both inside and outside the classroom all members of the school community are working together to raise boys into young men who are prepared and keen to take their places in society. Life Skills are therefore crucial to everything that we seek to achieve at the school.

'Life Skills' is taught from the Reception to year 8 as part of the boy's education and growth. Its main objective is to enable the boys to become healthy, independent and responsible members of the wider community by learning the basic principles for distinguishing between right and wrong.

In doing so, the boys are actively contributing to the pastoral life of the school and their surrounding community which in turn to develop their sense of belonging, self-worth and responsibility.

\section{Life Skill}

Life Skills are those abilities which may help on individual to lead a holistic and fruitful life. According to the world Health Organization (WHO) life skill are the abilities for adoptive and positive behavior the enables an individual to deal effectively with demands and challenges of regular life. Life Skills based education refers to the interactive process of teaching and learning which focuses on acquiring knowledge, attitude, values and skills which support behavior of the learner that enable them to take up greater responsibility in their lives by making healthy life choices gaining greater resistance pressures and minimizing harmful behaviors. According to UNICEF by Wikipedia life skills are behaviors used appropriately and responsibly in the management of personal affairs. They are a set of human skills acquired via teaching or through direct experience that are used to handle problem and questions commonly encountered in daily human life.

\section{Objective Of Life Skill}

Objective of like skill education to promote mental well being and competence in young people as they face the realities of life. Life Skill based education through school curriculum to help the learners to take positive approach to protect themselves and to promote health and meaningful social relationship life skills facilitate a complete and integrated development of an individual to function effectively do social being. Life Skill education system is a basic learning need for all individual. They are essential for various development and security.

The Promotion of primary preventions and protection for care to healthy child and adolescent development, Causes of various disease ,Changing social circumstances and socialization by preparing young generation people ,The issue of disability,Basic education system ,Gender Equality, democracy and good citizenship ,Quality and efficiency of the education system ,The promotion of peace, life long learning and emergence of life skills education.

\section{Life Skills Education Emerged As A New Vision:}

- Child right (CRC 1989)

- Jomtein Declaration on education for all (1990)

- UN conference on HIV/AIDS (2003)

- World programmed for Human Right Education (2004)

- UN Decade on education for sustainable Development (2005)

- UN secretary Generates Study on violence against children (2006) 
- $\quad 51^{\text {st }}$ commission on the status of women (2007)

Coping with stress Problem Solving Interpersonal Relationship Effective Communication Empathy Critical thinking creative thinking coping with emotion decision making self awareness core elements core Life Skills through (WHO). Life Skills Education (Approaches)
A. Special Study Approach
B. Extension Approach
C. Plug Point (Indirect)
D. As a Part of Curriculum (Direct)

\section{Curriculum - Life Skills}

The Life Skills program seeks to promote and develop the Every Child Matters outcomes, namely :

- To be healthy

- To stay safe

- To enjoy and achieve

- To make a positive contribution

- To achieve economic wellbeing.

- Integration

\section{Core Components Outcomes}

- Socialisation,role modeling benefit5ing both students in life skill program and the ICS mainstream program

- Trips

- Residential daily living skills, confidence,socialization,knowledge of environmentalism.

\section{Conclusion}

This paper reviewes the importance of life skills in our day to day life.Also, it helps to build our personality. Life Skills are those abilities which may help on individual to lead a holistic and fruitful life. The main aspect of like skill education is to promote mental well being and competence in young people as they face the realities of life. Life Skill based education through school curriculum to help the learners to take positive approach to protect themselves and to promote health and meaningful social relationship life skills facilitate a complete and integrated development of an individual to function effectively do social being.

\section{References}

[1] Botvin, G.J. (1986) Substance abuse prevention research recent development and future directions. Journal of School Health, 56(9). 369-373.

[2] CARICOM \& UNICEF. (1999). Health and Family Life Education: Empowering Young People With Skills for Healthy Living. An information package. Bridgetown, Barbados.

[3] Cheryl, L. et al., (1992). Models for Effective Prevention. Journal of Adolescent Health, 1992, 13. (5), 355-363.

[4] Choquet, M. Kovess (1993), Suicidal thoughts among adolescents: An intercultural approach. Adolescence, $28(11)$, pp 649-659.
} 